\title{
REPRESENTASI ANGKA ARAB SEBAGAI HURUF ARAB \\ DALAM TEKS BERBASIS INTERNET ${ }^{1}$
}

\author{
Eric Kunto Aribowo, S.S., M.A. \\ Universitas Widya Dharma Klaten \\ erickunto@unwidha.ac.id
}

\begin{abstract}
For some, it was the historical precedence of Latin script over Arabic in Internet. At times, the Arabic language was not supported by the widespread technology, thus Arabizi was the only possible way to communicate over the Net, and thus it was adopted. This is still valid, because some computer have no Arabic language capabilities. On the first level, the original Windows came in English and PC users found themselves constrained to use Latin script on their computers. On another level, Arabic keyboards are still not widely spread. Some computers do not have Arabic letters at all. Arabizi, a term that describes a system of writing Arabic in Latin script and the Arabic numerals, is now more popular than ever, especially online. To communicate with others in Arabizi, numbers are mixed to represent some letters in Arabic, such as 2, 3,6 , and 7 .
\end{abstract}

Keywords: Arabic script, Latin characters in Arabic, Arabizi

\section{A. Pendahuluan}

Abjad Arab dan bahasa Arab tulis mulai berkembang sejak abad ke-6 atau ke-7 Masehi, yang tentu saja berkaitan erat dengan penyebaran kitab suci Alquran. Tidak terdapat dokumentasi yang jelas berkaitan dengan perkembangan penulisan Arab sebelum masa itu dan terdapat jumlah yang sedikit mengenai teks-teks yang muncul pada periode pra-Islam, terkadang hanya dalam bentuk batu, prasasti, atau naskah.

Bahasa Arab memiliki sistem penulisan yang khusus layaknya bahasa China, Jepang, dan Rusia karena memiliki aksara khusus, tidak seperti bahasa Indonesia, Inggris, dan Spanyol yang menggunakan sistem penulisan yang sama dengan menggunakan huruf Latin. Menurut Wightwick (2005) terdapat beberapa prinsip dasar dalam penulisan aksara Arab: (1) terdapat 28 huruf, (2) penulisan dimulai dari kanan ke kiri, (3) tidak terdapat huruf kapital, dan (4) huruf ditulis dengan menyambung dengan huruf sebelumnya dalam sebuah kata (kecuali enam huruf: 1, , , ذ, J, j, dan و).

\footnotetext{
${ }^{1}$ Aribowo, E. K. (2013) "Representasi Angka Arab sebagai Huruf Arab dalam Teks Berbasis Internet," Pengembangan Peran Bahasa dan Sastra Indonesia untuk Mewujudkan Generasi Berkarakter, 1(1), hal. 249-254.
} 
Tabel 1 Huruf-huruf Arab (Hijaiah)

\begin{tabular}{|c|c|c|c|c|c|c|c|c|c|c|c|}
\hline j & $\mathrm{J}$ & ذ & د & $\dot{\tau}$ & $\tau$ & ج & $\dot{\Xi}$ & $ت$ & ب ب & 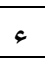 & Arab \\
\hline $\mathrm{Z}$ & $\mathrm{r}$ & $\dot{z}$ & $\mathrm{~d}, \underline{\mathrm{d}}$ & $\mathrm{kh}$ & h, $\mathrm{H}, \mathrm{h}$ & $\mathrm{j}, \mathrm{g}, \mathrm{dj}$ & $\dot{\mathrm{s}}, \mathrm{th}, \underline{\mathrm{t}}$ & $\mathrm{t}$ & $\mathrm{b}$ & ' & Transliterasi umum \\
\hline $\mathrm{z}$ & $r, r$ & ð & $\mathrm{d}$ & $\mathrm{x}$ & $\hbar$ & $\mathrm{j}$ & $\theta$ & $\mathrm{t}$ & b & $?$ & IPA \\
\hline $\mathrm{z}$ & $\mathrm{r}$ & $\mathrm{z}$ & d & '7 & 7 & $\mathrm{j}$ & $\mathrm{s}$ & $\mathrm{t}$ & $\mathrm{b}$ & 2 & Arabizi \\
\hline
\end{tabular}

\begin{tabular}{|c|c|c|c|c|c|c|c|c|c|c|c|c|c|c|c|c|}
\hline ي & 9 & $ه$ & ن & 5 & J & 5) & ق & ف & $\dot{\varepsilon}$ & $\varepsilon$ & ظ & b & ض & ص & ش ش & س \\
\hline y & $\mathrm{w}$ & $\mathrm{h}$ & $\mathrm{n}$ & $\mathrm{m}$ & l & $\mathrm{k}$ & $\mathrm{q}$ & $\mathrm{f}$ & $\mathrm{g}, \mathrm{gh}, \dot{\mathrm{g}}$ & ', A & $\mathrm{z}, \mathrm{Z}$ & ț, T & d, D & ș, $\mathrm{S}$ & sy, š & $\mathrm{s}$ \\
\hline $\mathrm{y}$ & $\mathrm{w}$ & $\mathrm{h}$ & $\mathrm{n}$ & $\mathrm{m}$ & $1, !$ & $\mathrm{k}$ & q & $\mathrm{f}$ & $\gamma$ & ؟ & д & $\underline{t}$ & $\stackrel{d}{d}$ & $\underline{s}$ & š & $\mathrm{s}$ \\
\hline $\mathrm{y}$ & $\mathrm{w}$ & $\mathrm{h}$ & $\mathrm{n}$ & $\mathrm{m}$ & l & $\mathrm{k}$ & 8,2 & $\mathrm{f}$ & '3 & 3 & '6 & 6 & '9 & 9 & sh & $\mathrm{s}$ \\
\hline
\end{tabular}

Karakteristik dasar tulisan Arab sering kali berkenaan dengan masalah tipografi yang apabila dibandingkan dengan tulisan Latin membutuhkan "jumlah karakter yang lebih besar". Inilah salah satu sebab pengadopsian huruf Latin ke dalam huruf Arab. Dalam bahasa Arab terdapat 28 huruf konsonan (Tabel 1). Kombinasi antara /lam/ J dan /alif/ I sering kali dianggap sebagai sebuah huruf, sehingga kebanyakan menyebut jumlah huruf Arab sebanyak 29 buah. Hamzah adalah sebuah tanda yang ditambahkan ke huruf lainnya (alif, waw, dan ya), dan dianggap sebagai variasi dari /alifl I. Vokal pendek direpresentasikan sebagai tanda vokalisasi yang berada di atas atau di bawah huruf (Gambar 1). Tanda vokalisasi, bagaimanapun juga, hanya digunakan dalam teks-teks tertentu (seperti dalam teks-teks pendidikan) atau bila diperlukan untuk mencegah kebingungan.

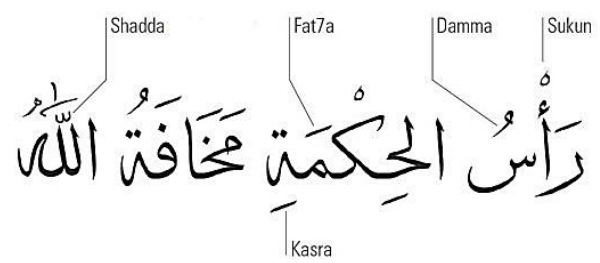

Gambar 1 Vokal Pendek dalam Bahasa Arab sebagai Tanda Vokalisasi

\section{B. Metodologi}

Sistem penulisan Arab-Latin yang diteliti adalah sistem penulisan yang dimanfaatkan dalam dunia internet, khususnya dalam teks-teks lirik lagu Arab yang di-upload pada alamat web http://www.songlyrics.com, http://www.allthelyrics.com, http://www.lyricsmode.com, http://www.arabiclyrics.net. Dari pranala ini didapati lirik-lirik lagu Arab yang ditulis dengan menggunakan tulisan Latin (non-Arab). Setelah ditemukan kata-kata yang diindikasikan berbeda dari sistem penulisan Arab-Latin yang populer, kemudian kata-kata tersebut dikelompokkan. Dilanjutkan dengan memvalidasi kata-kata tersebut dengan alamat web yang mengunggah teks-teks lirik lagu Arab dengan judul lagu yang sama bertulisan Arab seperti: http://www.l7nk.com, http://www.arabic-lyrics.com, http://www.la7oon.com/lyrics, dan http://fnanen.net. Selanjutnya, dilakukan perbandingan sistem penulisan Arab-Latin dengan sistem penulisan Arab. 


\section{REPRESENTASI ANGKA ARAB SEBAGAI HURUF ARAB}

Menurut Ghanem (2011) usulan untuk menulis bahasa Arab dengan huruf Latin sebenarnya telah lama diusahakan dalam rangka perluasan informasi dari media yang berbahasa Arab. Akan tetapi, sering kali perjuangan tersebut dikritik oleh nasionalis Arab dan penggemar Muslim, yang menganggap usaha itu sebagai serangan langsung terhadap identitas Arab. Dabbous (2013) juga melihatnya sebagai ancaman bagi Alquran, yang ditulis dalam bahasa Arab Klasik menggunakan sistem penulisan yang telah berlangsung selama lebih dari empat belas abad.

Saat ini, bagaimanapun juga, karena kemajuan internet dan penggunaan global dari penggunaan huruf Latin untuk menulis bahasa Arab melalui internet menjadi semakin umum. Arabizi, yang pada saat sekarang ini lazim digunakan dalam penulisan teks berbasis internet -termasuk juga media sosialmerupakan sistem penulisan bahasa Arab dengan menggunakan huruf Latin yang dikombinasikan dengan angka Arab. Angka Arab digunakan untuk mewakili huruf-huruf Arab yang tidak dapat ditemui dalam aksara Latin. Representasi angka Arab sebagai huruf Arab dalam teks berbasis internet yang ditemukan adalah sebagai berikut.

Representasi angka 2 sebagai huruf $₫$. Dalam sistem penulisan pada umumnya, huruf $\&$ (hamzah) sering kali diwujudkan sebagai apostrof $Y /$ dalam transliterasi. Adapun dalam sistem IPA yang direvisi tahun 2005 diwujudkan dengan [?]. Representasi angka 2 sebagai huruf $\&$ ditemukan antara lain dalam kata

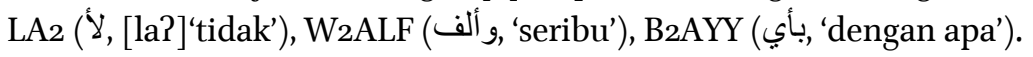

Representasi angka 3 sebagai huruf $\varepsilon$. Dalam sistem penulisan pada umumnya, huruf $\varepsilon$ ('ain) sering kali diwujudkan sebagai tanda koma di atas /\% dan /A/ dalam transliterasi. Adapun dalam sistem IPA yang direvisi tahun 2005 diwujudkan dengan [C]. Representasi angka 3 sebagai huruf $\varepsilon$ ditemukan antara lain dalam kata BA3ED (بعيد, [baYiid] 'jauh'), TA3ALA (تعال, [ta9a:la] 'mari'), 3AREF (عارف, [Tarrif] 'mengerti').

Representasi angka '3 (variasi lain 3 ') sebagai huruf $\dot{\varepsilon}$. Dalam sistem penulisan pada umumnya, huruf $\dot{\varepsilon}$ (gain) sering kali diwujudkan sebagai /g/, /gh/, / $\dot{\mathrm{g}} /$ dalam transliterasi. Adapun dalam sistem IPA yang direvisi tahun 2005 diwujudkan dengan $[\mathrm{\gamma}]$. Representasi angka '3 (variasi lain 3 ') sebagai huruf $\dot{\varepsilon}$ ditemukan antara lain dalam kata '3AREEB (غريب, [yari:b] 'aneh') dan '3ER (غير, [ye:r] 'kecuali').

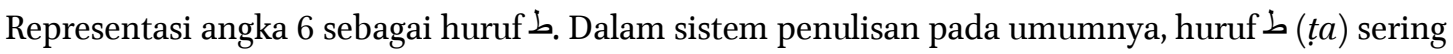
kali diwujudkan sebagai huruf $\mathrm{t}$ dengan tanda diakritis di bawahnya /ț/ dan /T/ dalam transliterasi. Representasi angka 6 sebagai huruf b ditemukan antara lain dalam kata '7E6 (خط, [xut] 'baris') dan 3ALA6OOL (على طول, [ 6 Galațul] 'terus').

Representasi angka 7 sebagai huruf $ح$. Dalam sistem penulisan pada umumnya, huruf $ح$ (ha) sering kali diwujudkan sebagai huruf h dengan tanda diakritik di bawahnya $/ \mathrm{h} /, / \mathrm{h} /$, dan $/ \mathrm{H} /$, dalam transliterasi. Adapun dalam sistem IPA yang direvisi tahun 2005 diwujudkan dengan [ $\hbar]$. Representasi angka 7 sebagai huruf $ح$ ditemukan antara lain dalam kata WA7ED (واحد, [wa:hid] 'jauh'), 7 OBBI (حبي, [hubbi:] 'cintaku'), 7ATTA (حتى, [hatta:] 'hingga').

Representasi angka ' 7 (varian lain 7 ') sebagai huruf $\dot{\tau}$. Dalam sistem penulisan pada umumnya, huruf $\dot{\tau}(k h a)$ sering kali diwujudkan sebagai huruf $/ \mathrm{kh} /$ dalam transliterasi. Adapun dalam sistem IPA yang direvisi tahun 2005 diwujudkan dengan [x]. Representasi angka '7 (varian lain 7') sebagai huruf $\dot{\tau}$ ditemukan antara lain dalam kata A'7ER (آخر', [a:xir] 'akhir'), BA'7AF (بأخاف, [baxa:fu] 'aku takut'), '7ALAS (خلاص, [xala:s] ‘sudah').

Representasi angka Arab ke dalam huruf sebagai sistem penulisan dalam bahasa Arab pada dasarnya digolongkan menjadi dua kriteria berdasarkan alasan ortografis atau ciri penulisannya. Pertama, representasi angka Arab sebagai huruf Arab berdasarkan kemiripan bentuk, termasuk di antaranya adalah 6, 7, dan '7 (atau 7'). Angka 6 memiliki kedekatan bentuk dengan huruf b dalam bahasa Arab, angka 7 berdekatan bentuk dengan $\tau$, dan angka ' 7 (atau 7 ') memiliki kemiripan dengan huruf $\dot{\tau}$. Kedua, perwujudan angka Arab sebagai huruf Arab karena refleksi atau cerminan bentuk, antara angka Arab dengan huruf Arab. Angka-angka tersebut adalah 2 yang merupakan refleksi bentuk dari huruf $\&$ serta angka 3 dan ' 3 (atau 3 ') yang merupakan cerminan dari huruf $\varepsilon$ dan $\dot{\varepsilon}$. 


\section{ALASAN PENGGUNAAN ANGKA ARAB SEBAGAI HURUF}

Menurut Ghanem (2011) beberapa pengguna merasa bahwa huruf Arab klasik harus digunakan untuk bahasa Arab Klasik dan bukan untuk keperluan non-formal. Mereka merasa lebih santai menggunakan sistem Arabizi untuk topik sehari-hari dan lagu dalam bahasa non-formal Arab. Lainnya menekankan bahwa mereka merasa bahwa Arabizi dapat mengekspresikan hal-hal yang tidak bisa diungkapkan sebaliknya.

Alasan yang utama penggunaan sistem penulisan ini adalah keterbacaan. Sering kali penulis dapati pesan singkat dalam sebuah telepon genggam atau teks dalam halaman sebuah tautan berbentuk

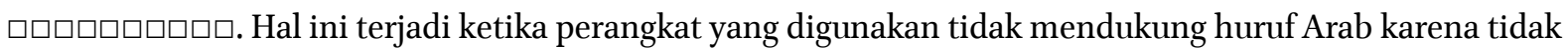
semua perangkat yang ada mendukung huruf Arab. Biasanya digunakan aplikasi pihak ketiga sebagai alternatif.

Alasan kuat yang lain penggunaan sistem penulisan ini adalah faktor ekonomis. Jumlah karakter dalam penulisan dengan huruf Latin cenderung lebih hemat jika dibandingkan dengan menggunakan huruf Arab, sebagai contoh, dalam telepon genggam yang penulis miliki, jumlah karakter yang dibutuhkan untuk mengetik '7ALAS (خلاص, [xala:s] 'sudah') adalah 6 buah karakter dengan sistem Arabizi dan 94 buah karakter dengan penulisan huruf Arab.

Selain kedua alasan di atas, menggunakan sistem Arabizi dianggap lebih mudah digunakan. Maksudnya, tidak memerlukan tanda diakritik dan tanda-tanda yang lain sebagai ciri pembeda huruf satu dengan huruf lain yang memiliki pola bentuk dasar yang sama. Selain itu, lebih mudah digunakan karena pengadopsian angka Arab sebagai huruf Arab berdasarkan kemiripan bentuknya.

\section{E. Penutup}

Berdasarkan analisis sebelumnya, dapat disimpulkan beberapa hal sebagai berikut. (1) Konsonan bahasa Arab memiliki beberapa kesamaan dengan konsonan yang digunakan dalam aksara Latin. (2) Beberapa konsonan membutuhkan gabungan huruf, seperti /sh/. (3) Konsonan-konsonan yang tidak terdapat dalam aksara Latin direpresentasikan dengan angka Arab. Perwujudan ini kebanyakan didasarkan pada kesamaan bentuk konsonan bahasa Arab yang asli dengan bentuk angka. Pada konteks ini, sebuah apostrof ditambahkan sebelum angka sebagai ganti tanda titik yang dibubuhkan pada beberapa huruf Arab untuk membedakan konsonan satu dengan konsonan yang lain yang memiliki bentuk dasar yang sama. Sebagai misal huruf $\tau$ dan $\dot{\tau}$ yang direpresentasikan oleh 7 dan ' 7 (atau 7 '). (4) Sistem penulisan ini tidak membutuhkan karakter khusus jika dibandingkan dengan sistem penulisan Arab-Latin yang lain, misalnya

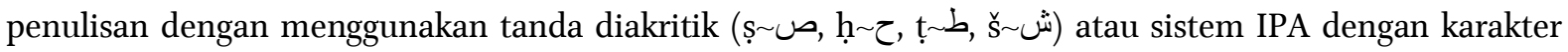

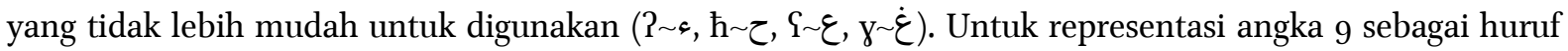
ص tidak/belum ditemukan karena sering kali dipadankan dengan $ث$ dan wang disebabkan oleh alasan dialektis. Adapun huruf ض dipadankan dengan huruf د dan huruf dengan huruf 2 . Hal ini disebabkan karena penulisan yang digunakan adalah ragam non-formal. Dalam ragam non-formal, pelemahan bunyi tersebut merupakan suatu hal yang normal atau wajar dalam bahasa Arab.

Penyebaran Arabizi membutuhkan perhatian lebih, dan desain tipografi yang dipromosikan dalam makalah ini hanya salah satu aspek. Pada tingkat pribadi, menggunakan karakter Latin tidak membawa manfaat langsung (ekonomis, misalnya), dan itu bukan suatu keharusan pada setiap tingkat teknis. Di sisi lain, misalnya ketika mengirimkan pesan dengan menggunakan sistem Arabizi akan jauh lebih murah daripada dalam bahasa Arab, dan, dalam beberapa kasus, hal ini diperlukan karena tidak tersedianya dukungan bahasa Arab dalam peralatan teknologi. Titik akhir untuk dicatat di sini adalah bahwa Arabizi menyebar tanpa proposal resmi, dengan cara diam, sebagai suatu keharusan karena penggunaan praktis. Bahkan mereka yang menolak penggunaan karakter Latin dalam bahasa Arab harus menggunakan Arabizi pada tautan halaman internet di mana mereka menerbitkan artikel mereka. 


\section{Referensi}

Abu-Chacra, Faruk. (2007). Arabic: An Essential Grammar. New York: Routledge.

Dabbous, Yasmine. (2013). Arabizi: Shu zam bi seer bi 3arabiyyitna? http://www.arabadmag.com/index.php?option=com content\&view=article\&id=116:arabizi-shu3am-bi-seer-bi-3arabiyyitna\&catid=19:may-2013\&Itemid=169 diakses 22 September 2013.

Ghanem, Renad. (2011). 'Arabizi is destroying the Arabic language'. http://www.arabnews.com/node/374897 diakses 22 September 2013.

Ryding, C. Karin. 2005. A Reference of Standard Modern Arabic. New York: Cambridge University Press.

Wightwick, Jane \& Mahmoud Gaafar. (2005). Mastering Arabic Script A Guide To Handwriting. New York: Palgrave Macmillan.

The International Phonetic Alphabet (Revised to 2005). 